\title{
A COLABORAÇÃO EFETIVA DO PEDAGOGO EMPRESARIAL NA FORMAÇÃO DE LÍDERES
}

\author{
Luiz Carlos Ferreira de Araújo ${ }^{1}$ \\ Anderson da Silva Matos ${ }^{2}$ \\ Cristiano do Nascimento Siqueira ${ }^{3}$
}

O presente artigo não esgota o assunto da Pedagogia Empresarial devido a sua complexidade, mas, investiga o Profissional da Pedagogia na formação da liderança observando as mudanças radicais provocadas pelo fenômeno da globalização, ponderando as características do universo complexo das empresas enquanto organizações em constante mudanças e adaptações mercadológicas. O objetivo é compreender as mudanças nas organizações em adaptarem-se a velocidade das transformações, identificando, conhecendo e estudando os novos modelos de gestão com suas respectivas técnicas, conceitos e métodos no que concerne o desenvolvimento de uma política pedagógica na construção de líderes organizacionais. O presente estudo foi realizado com base bibliográfica em livros, artigos, revistas e sites da internet, todos especializados sobre o tema por meio dos autores nacionais e internacionais. As transformações no universo globalizado são inevitáveis, os comportamentos, as culturas, climas e modelos de gestão são transformados constantemente para o desenvolvimento eficaz e eficiente das organizações para atingirem os seus objetivos, se reconhece que o "grupo de trabalho" foi transformado em "equipe", que o "chefe" tornou-se "líder educador", que o conceito e modelos de gestão estão humanizados, as técnicas são processos pedagógicos de ensino e aprendizagem, os conceitos mudam e adaptam-se as realidades circunstanciais. Na pós modernidade o conceito tradicional e autocrático de chefia está ultrapassado e sem espaço, quem não se adaptar estará fora das organizações que caminham na construção de uma política de liderança humanizada e educadora.

Palavras Chaves: Líderes. Liderança. Pedagogo empresarial. Formação de líderes.

\section{INTRODUÇÃO}

O surgimento de alguns eventos históricos, como por exemplo a descoberta da imprensa com Gutenberg, transformou a história da humanidade com grandes mudanças. Hoje, a humanidade sofre com as consequências geradas pelo fenômeno da globalização, a sua mudança mais radical foi o desenvolvimento tecnológico que provocou mudanças de concepções sociais que atingiu duramente a classe operária, neste contexto na perspectiva da educação não escolar, emergi a obrigação imprescindível de se ter um profissional que tenha a competência e as expertises didáticas e pedagógicas para lidar com essas transformações em prol das organizações privadas e ou públicas visando o aperfeiçoamento de seus colaboradores para benefícios mútuos, Severo faz a seguinte declaração sobre educação não escolar:

A inserção da Educação Não Escolar no âmbito pedagógico constitui-se como uma demanda histórica, pois responde às necessidades emergentes da complexidade que se revela no modo de estruturação e de comportamento das sociedades globalizadas. Por isso, é importante demonstrar o caráter pedagógico da Educação não escolar e ressalta a sua importância para a promoção de processos que potencializem a educabilidade humana em tempos nos quais as pessoas são confrontadas por múltiplas possibilidades e demandas de ensinar e aprender, de educar e de se educar. (SEVERO, 2017, p. 130). 
O universo da administração é pluralista, ainda é um tanto quanto inovador. O universo corporativo não é linear, está em constante mudanças e adaptações exigidas pelo mercado globalizado, neste contexto surge o desafio da inserção do pedagogo empresarial nas organizações, a pedagogia empresarial é o campo de atuação da pedagogia que visa trabalhar para o ser humano com o ser humano, valorizando, acompanhando a sua maturação e crescimento no âmbito empresarial e ou nas instituições públicas, Mendonça descreve os benefícios da pedagogia empresarial da seguinte forma:

\begin{abstract}
Desenvolve novas competências para compreender o negócio e as causas e os efeitos de certas decisões estratégicas. Permite adquirir novos insights sobre como a missão organizacional influencia as decisões cotidianas na organização. Visualiza novos horizontes combinando os novos insights e competências para ajudar aos colaboradores a verem mais claramente o que devem alcançar e como fazer isso. $\mathrm{O}$ colaborador se sente recompensada em seu trabalho, pois aprendendo e desenvolvendo habilidades e competências, as pessoas se sentem mais satisfeitas e realizadas com aquilo que fazem. (MENDONÇA, 2018).
\end{abstract}

A busca da melhora do desempenho das pessoas tanto na esfera pessoal como profissional, bem como da empresa em certo aspecto, é responsabilidade do Pedagogo Empresarial e ele o faz isso por meio das técnicas do ensino e aprendizagem desenvolvendo e ou reproduzindo estratégias, treinamentos e aplicações dos métodos pedagógicos, vejamos o que Morellato fala sobre o assunto:

Um dos espaços de atuação do Pedagogo dentro da empresa é na área de gestão de pessoas, colaborando constantemente para o desenvolvimento pessoal dos profissionais a fim de desenvolver cada vez mais as suas habilidades e capacidades, trazendo consequentes benefícios para a empresa e mercado em que a mesma está inserida (MORELLATO, 2020, p. 72).

Nenhuma empresa em sua razão de ser e de existir atua sem as pessoas, quer seja ela virtual e principalmente física, neste aspecto compreende-se que o bem maior de uma empresa são as pessoas, as ações de ordem prioritárias de uma empresa são as ações da gestão de pessoas vinculado ao RH (Recursos Humanos), e nesse sentido o pedagogo empresarial desenvolve um papel muito importante na empresa na formação de sua liderança, ele é o responsável direto pela provocação na mudança de comportamento nas pessoas, todo indivíduo motivado e capacitado tecnicamente sente-se bem em produzir muito mais, consecutivamente a empresa desenvolve e conquista maiores e melhores resultados bem como o aumento de sua lucratividade, sobre o assunto Morellato faz a seguinte afirmação:

O pedagogo, portanto, com toda a sua formação e qualificação didática, pode atuar dentro da empresa com elaboração de projetos e treinamentos que visem ao desenvolvimento humano. Com isso, nota-se a intensa relação das capacidades utilizadas em espaços escolares, presente no espaço não escolar. Esse profissional tem a capacidade de encontrar as reais necessidades a serem trabalhadas no ambiente em 
que está inserido e qual deverá ser a prioridade a ser abordada. (MORELLATO, 2020, p.72).

Considerando a afirmação da autora, o pedagogo empresarial, tem que ter conhecimentos de diversas áreas do saber, como por exemplo, psicologia, sociologia, antropologia, filosofia, e andragogia, com a sua formação ele deve contribuir para que a empresa desenvolva relacionamentos saudáveis, promovendo com a sua direção e ou conselho, atividades que desenvolvam as interações interpessoais e formando uma liderança eficiente e eficaz.

O Pedagogo Empresarial que trabalha gerindo pessoas, constrói a sua liderança estrategicamente, por meio da "tomada de decisão, o profissional precisa estar atento às diversas transições e dinâmicas do contexto profissional, conhecendo-o e se adaptando", Forcione e Barbato (2017, p. 353), educando, formando líderes e delegando pessoas para o desempenho de atividades com a finalidade da implantação e desenvolvimento de um projeto que inclui ações pedagógicas como um elemento interno, e de ações sociais como um elemento também interno e externo onde há o envolvimento com a sociedade, sobre essa questão Fonseca faz a seguinte consideração:

O pedagogo deve se ligar às funções de formação, treinamento e desenvolvimento, capacitação, planejamento de programas e atividades ligadas à educação empresarial. Estas atividades de aperfeiçoamento profissional, assessoramento e apoio, contribuem de modo positivo para com a gestão de pessoas. O pedagogo deve ser um profissional capacitado para lidar com fatos e situações diferentes da prática educativa em vários segmentos sociais e profissionais. (FONSECA, 2016, p. 17).

Apesar das dificuldades inerentes na formação e treinamento de líderes, a realização de novas pesquisas é de fundamental importância, com o intuito de promover o desenvolvimento e fortalecimento da Pedagogia Empresarial. Para testificarmos e contribuir com a formação e treinamentos de líderes no meio corporativo, a proposição de nossa investigação é de cunho bibliográfico.

O desenvolvimento do método e técnicas de estruturação educacional proveniente do pedagogo empresarial visa a supervisão das atividades delegadas conforme o planejamento, que faz parte do processo inicial da educação, do amadurecimento e crescimento do perfil profissional e pessoal durante a sua vida. Igualmente como todo profissional dedicado, o Pedagogo é alguém que busca perseverantemente o aprimoramento de sua formação em suas diversas esferas de relações interpessoais, na família, onde reside, no trabalho, na universidade e na sociedade. Fonseca afirma o seguinte: 
Além de possuir visão generalista e humanística, pode-se dizer que, dentro de uma organização, o papel do pedagogo também tem seu lado específico na área administrava, ou seja, ele planeja, organiza, coordena, executa, analisa, assessora, controla e avalia programas os projetos educacionais dentro da empresa. O pedagogo deve acompanhar todo o desenvolvimento do funcionário, o seu desempenho, direcionando-o para o caminho que este deve seguir dentro da empresa, facilitando, enquanto agente provocador de mudança de mentalidade e de cultura. (FONSECA, 2016, p. 17, 18).

De modo geral a administração é dividida em 5 áreas distintas, são elas: Finanças, Logística, Vendas ou Produção, Recursos Humanos, e Marketing. Na perspectiva da globalização as mudanças, inovações, e transformações que ocorrem em grande velocidade, em meio às tais transformações encontramos novos desafios dentro das corporações, o recrutamento e treinamento de novos líderes. O que é liderar? Não podemos ter a pretensão de conceder e ou criar uma única definição tendo em vista que o universo da liderança é muito abrangente, França nos mostra a seguinte definição:

O líder é a pessoa que tem a habilidade de motivar e de influenciar os liderados, agindo de forma ética e positiva, de modo que contribuam voluntariamente e com entusiasmo para alcançarem os objetivos da equipe e da organização sempre explorando de cada membro da equipe os seus pontos fortes. No entanto, a liderança pode ser complexa, pois o bom líder, além de habilidades técnicas, deve ter inteligência emocional para gerir os colaboradores e a equipe, ser capaz de desenvolver seus liderados atendendo expectativas pessoais e profissionais, e tudo isso sempre alinhando com os interesses das organizações. (França, 2017).

Se considerarmos que liderar é fazer coisas com e por meio de pessoas teremos a seguinte definição por Nascimento e Bryto:

Liderança, entre outras definições, é a capacidade de influenciar e esta influência se constrói com base em bons relacionamentos. O líder constrói bom relacionamento com a equipe a partir do momento que conquista confiança de seus liderados. A liderança eficaz tem seu alicerce na confiança, presente nos relacionamentos da equipe, do líder com os liderados e vice-versa, para tanto, inicialmente, o compartilhamento e transparência das metas se faz necessário, tanto da organização quando da equipe dentro do objetivo maior. (NASCIMENTO e BRYTO, 2019, p. 32).

Ao promover e desenvolver estrategicamente líderes, o Pedagogo deve expor pormenorizadamente todas as atividades de forma bem clara, coerente, coesa, consistente e emocionalmente contagiante. Com o advento tecnológico a vida em sociedade mudou drasticamente, profissões extinguiram-se, novas surgiram, e outras foram transformadas, isso nos leva a perspectiva da pluralidade de se fazer algo de maneira diferenciada, considerando tal fato a liderança não só possui diversas definições, como também existem tipos diferenciados de lideranças e ou de líderes tais como: Autoritário, Carismático, Motivador, Especialista, Liberal, Democrático e Coaching, vejamos as seguintes definições por Marques:

1. O líder autoritário 
Esse tipo de líder é mais conhecido como big boss. Ele manda e desmanda e não se importa com a opinião de mais ninguém. Costuma tomar suas decisões com base no que ele mesmo acha e não ouve a opinião dos outros, afinal, o chefe é ele.

\section{O líder carismático}

Esse tipo de liderança é muito comum em empresas que conseguem chegar ao sucesso e que possuem funcionários fiéis. Por quê? Porque o carisma do chefe faz com que os colaboradores se tornem profissionais apaixonados pelo dia a dia da empresa.

\section{O líder motivador}

A especialidade do líder motivador é inspirar todos ao seu redor, fazendo com que cada liderado se doe ao máximo. Com todos juntos nessa atmosfera de cooperação, são obtidos resultados que seriam inimagináveis em uma equipe limitada.

\section{O líder especialista}

O líder especialista é aquele indivíduo que chegou até tal posição não por sua capacidade de se relacionar com as pessoas, por sua habilidade de influenciar os profissionais ao seu redor ou qualquer outra coisa do tipo. Ele até pode ter essas características, mas o que permitiu que ele se tornasse um líder é o seu conhecimento avançado em determinada área do conhecimento.

\section{O líder liberal}

Pense no conceito de liberalismo: diversidade, liberdade e pouca intervenção do Estado. Trazendo isso para o âmbito empresarial, temos um líder que dá total espaço para os seus colaboradores, permitindo que eles se sintam à vontade para criar, para desenvolver e para ter ideias inovadoras. Essa característica de liderança é sempre bem-vinda quando a equipe é madura e, claramente, não precisa mais de um tutor fiscalizando o desempenho a todo instante. Quando os profissionais já trabalham há muito tempo juntos, pode ser uma boa sugestão.

\section{O líder democrático}

Quando o líder acredita que a participação de todos os seus colaboradores na tomada de decisões é importante, temos uma liderança democrática. Esse tipo de líder não é autocrático e autoritário, mas também não é tão liberal a ponto de deixar a própria equipe tomar as suas decisões. Ele está no meio do caminho entre esses dois extremos, pois oferece opções e ouve as opiniões de seus liderados, frequentemente promovendo votações para a tomada de decisões.

\section{O líder coach}

Além dos 6 perfis de líderes apresentados acima, há também um perfil de líder bastante completo e necessário nas organizações nos dias atuais: o líder coach! Mas o que distingue esse líder dos demais? O líder coach é alguém que alia liderança aos princípios e técnicas do coaching. O gestor que sabe se automotivar, que tem suas metas muito bem claras e definidas, que determina que todas as suas ações possuam propósitos delineados e que está pronto para lidar com os diferentes obstáculos que surgirem no seu cotidiano profissional é um líder coach. (MARQUES, 2021).

A liderança Coach tem sido crescente no meio corporativo, por questões culturais ainda temos resquícios dos outros modelos de liderança sobrevivendo no mundo corporativo, o pedagogo empresarial deve manter-se alerta constantemente, as organizações empresariais são constituídas de diversos tipos de pessoas, com suas crenças e valores morais distintos, com ideologia política partidária, aspectos culturais, portanto cabe ao pedagogo ter o conhecimento 
devido das pessoas para que a corporação possa desenvolver satisfatoriamente as suas metas, a docente Taísa Silveira faz a seguinte afirmação:

Entre as variadas funções, cabe a este profissional desenvolver habilidades que permitam a relação empresa-funcionário compreendam o negócio, as causas e os efeitos de certas decisões estratégicas. Destacam-se tarefas como:

1. Execução e expansão de conhecimentos entre a equipe de colaboradores;

2. Metodologias quanto ao uso de tecnologias em prol da empresa;

3. Gestão de pessoas;

4. Planejamento;

5. Intervenções de medidas e políticas de educação em órgãos públicos ou privados, etc. (SILVEIRA, 2017).

Considerando as responsabilidades citadas, ainda existem outras diversas situações a serem superadas para implementar na prática os projetos: a) a falta de conhecimento técnico dos gerentes; b) a formação acadêmica não é a única ferramenta intelectual para o gerenciamento e ou a liderança; c) alguns gerentes ou líderes não possuem a competência devida para o exercício da liderança, gerir pessoas, ousadia para encarar os desafios, visão empreendedora e renovadora. Antonyk faz a seguinte observação sobre o assunto:

O comportamento do gerente do século XXI já deveria ter mudado. Mas gestores autocráticos continuam se multiplicando dentro das organizações. As empresas permanecem enfrentando dificuldades para melhorar a produtividade e, com o intuito de encontrar um líder que as leve ao sucesso, substituem com frequência os executivos do quadro gerencial. (ANTONIK, 2016, p. 222).

Perante a grande concorrência do atual mercado, torna-se primordial que todo profissional incumbido da posição de liderança, seja responsável, comprometido, competente, ético, justo, capaz de aprofundar-se no conhecimento que tange as perspectivas do comportamento humano, perceber as mudanças provocadas pela influenciação de suas atitudes, bem como, o âmbito dos valores existentes, nesse sentido, Branco faz a seguinte afirmação:

\footnotetext{
As empresas que buscam um bom posicionamento no cenário econômico atual devem enxergar na educação corporativa uma vantagem competitiva em relação aos seus concorrentes, para tanto, é necessário um ensino-aprendizagem diferenciado na organização, isso requer a presença de um pedagogo empresarial para conduzir um processo didático alinhado as necessidades da empresa. As profundas alterações no mundo empresarial vêm, concomitantemente, acompanhadas por uma intensa modificação nas atividades empresariais voltadas à educação corporativa, o que leva as empresas a destinarem maior atenção e investimentos nessa área, mas com a utilização aquém do necessário do profissional de pedagogia nesse processo. (BRANCO, 2019, p. 18).
}

A reflecção sobre a pedagogia empresarial, conduz ao entendimento que o pedagogo empresarial deve estar consciente que o processo educacional no meio coorporativo é abrangente, o ato de educar não é meramente uma forma de transmitir técnicas e informações, Torres e Vilela argumentam da seguinte maneira:

A Pedagogia Empresarial, porém, tem o objetivo de implementar programas de qualificação, disseminando o conhecimento, traçando estratégias e metodologias que 
certificam uma melhor aprendizagem dos funcionários. Cabe à Pedagogia Empresarial valorizar o potencial de cada colaborador, respeitando sempre o limite de aprendizagem de cada um. (TORRES e VILELA, 2018, p. 4).

Ao considerar esse aspecto, ele desenvolve e aplica a sua liderança por meio de ações na área das relações interpessoais, planeja, organiza, geri e avalia o desempenho dos seus liderados, o mesmo não desenvolve as suas ações pedagógicas, sociais, burocráticas e administrativas sozinho, ele está ligado com à área de Recursos Humanos. Lima faz a seguinte colocação:

As funções do pedagogo empresarial, pelo que se observa, englobam os conhecimentos tanto da prática pedagógica como da prática administrava, por este motivo, o seu envolvimento com a área de recursos humanos é tão importante, para que consiga modificar os comportamentos dos funcionários das empresas, agreguem conhecimentos, habilidades, atitudes e comportamento e, consigam tornar a empresa mais competitiva, consequentemente, com maior lucratividade. (LIMA, 2016, p. 16).

Aquilo que lhe compete em suas ações profissionais, aliada as experiências de outros profissionais de outras áreas, é de suma importância nas suas ações e na gestão de pessoas visando coletivamente à melhoria dos resultados desejados pela empresa, educar não consiste em apenas transmitir técnicas e informações. "A educação tem como finalidade a instrumentalização do homem (a prática), bem como a instrumentalização filosófica (a teoria), capacitando-o a agir sobre o mundo e a época em que vive e, simultaneamente, abrigar em si a compreensão à ação exercida” Romero (2019, p. 20).

A corporação empresarial deve possibilitar o crescimento de seus funcionários como um todo, não se busca características perfeccionistas aliadas às técnicas dos associados na execução de suas tarefas. É necessário um profissional especializado, que seja qualificado em executar as ações educacionais de forma coordenada e planejada, Alves faz s seguinte observação:

Seja dentro da escola ou dentro da empresa a pedagogia tem objetivos predefinidos de transformação da realidade, favorecendo mudanças nos comportamentos das pessoas. E a atuação do pedagogo na empresa deverá seguir os princípios de filosofia e política dos recursos humanos aplicados pela corporação, aliado a conhecimentos pedagógicos para realização dessa transformação pessoal de cada indivíduo. (ALVES, 2018, p. 19).

Inicialmente a profissão de Pedagogo Empresarial foi instituída entre as décadas de 50 e 60, o ramo da Pedagogia Empresarial é relativamente recente, a educação no universo do trabalho nas estruturas e organizações empresariais é uma possibilidade da ação pedagógica na sociedade. Segundo Alves:

A educação anda lado a lado com a sociedade em todos os contextos, sejam eles econômicos, culturais e sociais. Desse modo, se tornou papel da educação estimular o indivíduo por meio de sua criatividade e iniciativa à elaboração de novos recursos para melhor desenvolvimento profissional em seu ambiente de trabalho, ou seja, é 
papel da educação estimular também o desenvolvimento profissional de cada ser humano. Portanto, a pedagogia empresarial surgiu, nesta perspectiva, para dar assistência no que diz respeito à estruturação de mudanças, ampliação e aquisição de conhecimento no meio corporativo. (ALVES, 2018, p. 5-6).

A obtenção do conhecimento tornou-se um elemento imprescindível no mundo do trabalho, considerando a globalização e o avanço tecnológico, as corporações percebem a necessidade de reformular suas técnicas e práticas para acompanhar o novo modelo de gerir e ou liderar respaldado na economia do saber, Silva e Souza dizem o seguinte:

No cenário atual, o profissional não mais será treinado para exercer uma única função, é necessário que este esteja em constante processo de aprendizagem e acompanhando os avanços tecnológicos e necessidades da empresa, como também o pedagogo empresarial utilizar das novas tecnologias para melhorar o desempenho dos treinamentos. Como se pode perceber, a pedagogia empresarial é chamada a se renovar e acompanhar as exigências da educação e do mundo no século XXI. (SILVA e SOUZA, 2018, p. 93).

O Pedagogo Empresarial por meio do desenvolvimento de suas ações concernente as suas prerrogativas, deve orientar e conduzir a educação na perspectiva da operacionalidade do trabalhador na empresa por meio da inserção de atividades pedagógicas educacionais, visando à educação do trabalhador no universo empresarial, Rocha faz a seguinte declaração:

A pedagogia atua e trabalha encima de métodos e estratégias que provocam mudanças
nas pessoas, melhorando e ampliando a qualidade de vida delas e consequentemente
ampliando a capacidade de trabalho do indivíduo consideravelmente. O trabalho do
pedagogo ainda nos ensina que devemos ter um olhar humano, aprender a conhecer o
seu próprio interior e também conhecer e compreender o outro, além de nos ensinar a
planejar, sistematizar, fomentar e elaborar projetos aumentando a qualidade e
produtividade da empresa. (ROCHA, 2019, p. 196).

Considerando os aspectos técnicos da aplicabilidade prática da liderança, recai sobre o pedagogo empresarial a devida responsabilidade e competência da interação com outros líderes dentro da infraestrutura empresarial, e neste sentido ele deve ter a desenvoltura necessária para orientar, ensinar e inspirar pessoas e transformar situações, um verdadeiro líder possui uma posição estratégica na organização, é primordial que a liderança seja usada para motivar e inspirar os colaboradores em vencer. Carpes faz a seguinte afirmação:

Em um ambiente de constante evolução, cabe às empresas se reinventarem constantemente a fim de atender e sobreviver ao mercado. Para que isso aconteça, se faz necessário aos líderes a capacidade de gerar novas organizações, motivar equipes, inspirar seus colaboradores, entre outras características. (CARPES, 2017, p. 49).

O desenvolvimento da construção do conhecimento é árduo, entretanto, é um nobre exercício que exige desprendimento. O pedagogo é unicamente o profissional capacitado e com a devida formação acadêmica para executar essa nobre incumbência. Vejamos como Borelli elenca o papel de um líder educador: 
Proporcionam iniciativas de aprendizagem, favorecendo treinamentos sobre tarefas específicas no local de trabalho;

Incentivam o envolvimento de todos os colaboradores nas iniciativas de aprendizagem da área e da organização;

Estimulam a troca e a divulgação de conhecimento entre os colaboradores;

Fazem uso do conhecimento já existente na organização, quando disponível e oportuno;

Favorecem a transformação do conhecimento em ações, dando espaço e criando oportunidades para os colaboradores colocarem em prática o que aprendem, com autonomia e reponsabilidade;

São "líderes professores" naquilo que podem agregar de conhecimento e habilidades; Assumem a responsabilidade pelo desenvolvimento de seus liderados e servem de exemplo. "Faça o que eu falo, mas não faça o que eu faço", não funciona em liderança. Ações são mais relevantes do que palavras. (BORELLI, 2018, p. 319-320).

Naturalmente, todo líder deve ser capaz de exercer adequadamente a persuasão e influenciação como ferramentas de sua capacidade de liderar, e nesse sentido exercendo seu papel, a capacidade de influenciar vai além do que dizer como deve ser feito. "Liderança é o processo de desenvolver ideias e uma visão. É viver de acordo com valores que deem suporte a tais ideias e visão, influenciando pessoas, comportamentos, bem como tomar decisões", Barbosa (2018, p.172). O processo de influenciar deve conduzir as pessoas para uma ação educadora, o indivíduo se tornará uma pessoa consciente de seu valor para a sua equipe, bem como para a organização, quando um colaborador torna-se consciente de sua importância e da valorização do senso de equipe, ele mostrará o seu melhor para atingir os objetivos estabelecidos. Toda liderança estará interligada aos resultados, a obtenção do mesmo passa por uma extensa demanda de conhecimento como afirma Moreira e Silva:

Com o cenário de competitividade e o alto grau de exigências por resultados sendo crescentes a cada instante no mundo corporativo, as organizações estão cada vez mais rigorosas com a formação de seus líderes, pois quando exercida de forma adequada possibilitará melhores resultados para a organização. (MOREIRA e SILVA, 2017, p.248).

No exercício estratégico de sua liderança o Pedagogo Empresarial deve ser capaz de ter uma cosmovisão macro dos colaboradores da equipe e consecutivamente das condições do ambiente do trabalho, só assim ele terá as condições necessárias para a condução da(s) equipe(s) para a conquista dos resultados esperados, "a vontade de aplicar estratégias, fazer e ser o diferencial são individuais, no entanto, os líderes e os liderados devem estar alinhados para que os resultados favoreçam o crescimento de todos", Pereira (2019, p. 96). Mudanças sempre são necessárias para o desenvolvimento e crescimento de qualquer organização, "várias pessoas precisam contribuir com a tarefa de liderança, não tentando imitar as inclinações de Winston Churchill ou de Martin Luther King Jr., mas participando modestamente do programa de liderança em suas esferas de atividade”, Kotter (2017, p. 30), a velocidade das mudanças em detrimento a globalização, não é a mesma velocidade de mudança quando se trata de pessoas, 
adequação de projetos, um novo sistema, novas técnicas e filosofias de trabalho podem ser concebidas com pouco tempo, "em uma sociedade com constantes e rápidas mudanças sociais, culturais e econômicas, é importante que as empresas acompanhem essa dinamicidade, o que as obriga a se reinventarem para se adaptarem, Aguiar e Machado" (2017, p.89), mas, a implementação não terá a mesma velocidade, as pessoas precisam de preparo, orientação, reeducação ao novo sistema, o sistema antigo e obsoleto deve ser sistematicamente substituído em detrimento do novo, neste aspecto o pedagogo empresarial deve ter a sensibilidade e ter a percepção que os colaboradores em geral não aprendem na mesma velocidade e quando essa transição não ocorre adequadamente é prejudicial ao sucesso da organização, a mudança atinge todos os colaboradores, ressalta-se que a gestão, tem a primazia em ser educada para a mudança, "identifique os agentes de mudança. Capacite a equipe para pensar criativamente. Comunique. Comunique. Comunique mais" Wheeler (2019, p. 198). Não é concebível na nova infraestrutura organizacional da organização implantar algo que não seja pelo processo pedagógico de ensino, e nesse aspecto o único profissional suficientemente capaz é o pedagogo empresarial, a mudança de mentalidade, comportamento e etc... Atinge a todos os cargos dentro de uma organização, "para que as ações tenham resultados é preciso que haja estruturação das ideias e de como tudo será realizado, pois sem isso todas as contribuições serão em vão e as pessoas não saberão o que cada uma deve fazer dentro do processo", Barbosa (2018, p. 182), compreendendo que ainda estamos em um período veloz de transição o pedagogo enfrenta e enfrentará diversos desafios nas corporações, por outro lado "os desafios provenientes de tarefas diárias são excelentes motivadores. O próprio prazer no trabalho é um motivador”, Cunha (2018, p.13), o pedagogo deve ter um discernimento devidamente aguçado para implementar uma estratégia pedagógica para moldar e transformar a realidade de seu contexto, "para dar foco e conduzir uma ação sustentável, um líder precisa enquadrar a informação. Assim os dados complexos podem ser compreendidos como parte de um padrão. Uma solução para o enquadramento eficaz é encontrar padrões comuns para organizar ideias diversificadas", Ulrich e Smallwood (2019, p.38), apesar disso compreende-se também que é intrinsecamente necessário ter em mente, o que um líder não pode ser e não deve fazer, não é suficiente apenas diagnosticar problemas e ter uma estratégia de solução, é evidente que ter toda essa desenvoltura é necessário, mas o pedagogo empresarial em suas ações na organização deve ter a habilidade de perceber quando o seu projeto pedagógico de ensino está sendo minado, para isso ele deve conhecer as seguintes características que exemplificam o que a liderança e ou líder não podem fazer: 
1. Um líder não perde tempo sentindo pena de si mesmo.

Mas assume a responsabilidade de seu papel e entende que a vida nem sempre é fácil ou justa.

2. Não transfere seu poder para os outros.

Um líder não permite que outros usem seu poder em seu lugar. E não diz coisas como "meu chefe me fez sentir mal" porque ele sabe que está no controle de suas emoções e pode escolher como responder a situações de estresse.

3. Não se priva de mudanças.

Líderes não temem mudanças, pelo contrário, são flexíveis e ávidos por mudanças positivas.

4. Não perde energia em coisas que não pode controlar.

Você não vê pessoas mentalmente fortes reclamando da mala perdida ou do trânsito. Elas focam no que elas podem controlar, e sabem que, algumas vezes, a única coisa que podem controlar é sua própria atitude.

5. Não se preocupa em ser amável com todos.

Líderes não têm medo de dizer não ou discutir quando necessário. Eles desejam ser gentis e justos, mas podem conviver com o fato de que não agradarão sempre.

6. Não tem medo de correr riscos calculados.

Eles não correm riscos imprudentes, mas não se importam de correr riscos calculados - e perdem bastante tempo pesando os riscos e os benefícios antes de tomar uma grande decisão.

7. Não se debruça sobre o passado.

Pessoas fortes não perdem tempo desejando que as coisas fossem diferentes. Elas reconhecem seu passado e dizem o que aprenderam com ele, mas não fantasiam com dias gloriosos. Vivem o presente e planejam o futuro.

8. Não repete erros.

Além de aceitar a responsabilidade sobre seu comportamento, líderes aprendem com erros do passado - o que evita repeti-los.

9. Não se ressente do sucesso alheio.

Inveja é algo que não passa na cabeça de líderes. Eles gostam e celebram o sucessos dos outros, e sabem que terão de trabalhar duro para ter sua própria oportunidade.

10. Não desiste depois do primeiro fracasso.

Eles não veem o fracasso como uma razão para desistir, mas o usam como uma oportunidade de crescer e se aperfeiçoar.

11. Não tem medo de ficar sozinho.

Líderes toleram ficar sós e não têm medo do silêncio - não são dependentes de companhia. Ficar sozinho com seus pensamentos aparentemente não é um problema - e usam esse tempo de forma produtiva.

12. Não acha que o mundo o deve alguma coisa. 
Pessoas fortes não nasceram com a mentalidade de que os outros devem cuidar delas ou que o mundo as deve alguma coisa. Em vez disso, veem as oportunidades com base em seus próprios méritos.

13. Não espera resultado imediato.

Trabalhando ou investindo na saúde, nossos líderes do futuro não esperam resultados imediatos. Por outro lado, aplicam suas habilidades e tempo para entender que mudanças reais levam tempo. (LOPES, 2021).

Entende-se que os “erros" acima elencados por Lopes possivelmente estão presentes, em sua totalidade ou parcialmente, em diversos gestores que se autodenominam de líderes, se os supostos líderes não estão dispostos a corrigirem e ou superarem os seus vícios, por consequência não há como melhorarem a sua liderança, contrapondo-se a essa situação, a verdadeira "liderança tem que acontecer por meio da ligação com os outros", Ulrich e Smallwood (2019, p. 207). Negativamente existem circunstâncias e situações, em que colabores confessam que nas empresas que trabalham, os supostos líderes afirmam a sua preocupação com a interatividade e participação de todos os colaboradores, mas não desenvolvem e nem se envolvem em nenhum processo de mudança, os verdadeiros líderes "são capazes de sustentar a mudança na organização quando conseguem identificar e monitorar indicadores precoces", Ulrich e Smallwood (2019, p. 146). O descaso dos vaidosos que se convenceram que são líderes é um agravo para o crescimento da corporação, a situação é drástica em alguns casos que os mesmos não possuem os conhecimentos técnicos que são inerentes ao seu cargo suficientemente necessárias para o andamento do trabalho a eles designado, nesses casos o feedback ocorre apenas quando é negativo, Ulrich e Smallwood avaliam da seguinte forma:

As consequências negativas geralmente tem um impacto a curto prazo, impulsionando a mudança de comportamento por causa do medo. Quando essas pressões são removidas, os comportamentos originais começam a voltar, porque todo ato de obediência forçado foi acompanhado de pensamentos sobre o que teria sido feito caso não existisse ameaça de punição. As consequências positivas tendem a exercer um efeito de prazo mais longo sobre o comportamento reforçado repetidamente pelos resultados desejados se tornem habituais. (ULRICH e SMALLWOOD, 2019, p. 101).

O comportamento em sociedade é cheio de modismos, e muitas pessoas se deixam levar por essas influências, quando esse tipo de comportamento atinge as organizações empresarias ocorre a implantação de novos processos de gestão sem critérios, sem o devido conhecimento técnico e pedagógico ou simplesmente sem a menor compreensão da realidade, entende-se que na maioria das vezes são organizações que possuem um sistema de gestão falidos, não possuem as condições necessárias para a sustentabilidade e a devida qualificação de seus líderes para que possam desempenhar com profissionalismo a condução da equipe de trabalho de forma coesa e coerente com todos os objetivos pedagogicamente e estrategicamente definidos. Ulrich e Smallwood falam o seguinte sobre a condução do trabalho em equipe: 
Líderes que asseguram a sustentabilidade se certificam de que está claro para a sua equipe o que se espera de cada jogador e da equipe como um todo, e de que todos os participantes sabem que seu desempenho está sendo monitorado e exibido de forma transparente e oportuna. Sem medidas transparentes e oportunas, os colaboradores não sabem onde estão - e não sabem o que devem saber para melhorar. (ULRICHE e SMALLWOOD, 2019, p. 147).

No desenvolvimento do exercício de sua liderança, o Pedagogo Empresarial deve aprimorar alguns de seus principais papéis para obter sucesso em sua função como educador e influenciador do processo pedagógico da aprendizagem. Determinadas organizações por meio de alguns indicadores, estão tendo uma determinada percepção quanto ao envolvimento dos líderes no processo pedagógico educacional corporativo e possuindo a compreensão que estes líderes devem firmar o seu papel como educadores, visando o sucesso do projeto pedagógico dentro do sistema. Shinyashiki elenca os seguintes papeis do líder educador:

O líder educador não só ensina, mas também aprende com os liderados.

Ele não apenas delega, mas também realiza juntamente à equipe em busca dos melhores resultados.

A liderança educadora verifica constantemente se as pessoas estão motivadas para o desenvolvimento e entrega de resultados no trabalho.

Os líderes educadores têm forte empatia pelas pessoas e se interessam pelo trabalho de sua equipe.

Existem algumas atividades que estão relacionadas ao dia a dia do líder educador como integração, desenvolvimento da comunicação, gestão do tempo e o desenvolvimento do potencial profissional de sua equipe.

O líder que possui a essência educativa gerencia sua equipe por meio do diálogo. Ele define sua gestão como um espaço de aprendizagem para o desenvolvimento de novas competências e estimula o compromisso com a equipe e demais pessoas, criando um melhor ambiente de trabalho e possibilitando mais qualidade e inovação. (SHINYASHIKI, 2017).

Em certos aspectos a visão de Shinyashiki tem características inovadoras e audaciosas, é necessário acompanhar as transformações e mudanças do universo do "fenômeno da globalização vem provocando alterações significativas no mundo contemporâneo trazendo muitas vezes consequências incertas e indeterminadas para a sociedade, além de modificar a relação entre os Estados Nacionais”, Rover (2019, p.13), se faz necessário que as organizações empresariais desenvolvam as capacidades e devidas competências de fazer uma leitura correta do mercado e as suas tendências, ter apenas profissionais atualizados, competentes, eficazes e eficientes não é suficiente, é preciso ir mais longe, é necessário ter uma visão futurista para a sobrevivência da corporação, algumas organizações despertaram para essa questão de tal forma que desenvolveram o seu próprio centro educacional, toda e qualquer empresa deseja possuir funcionários que sejam comprometidos com os valores, missão e visão da mesma, a obtenção desse sucesso dar-se-á por meio de um planejamento pedagógico, segundo Branco: 
A proposta do projeto pedagógico empresarial procura desenvolver integralmente o profissional para:

Ser capaz de dominar os diversos conteúdos desenvolvidos na empresa, conquistar um repertório de saberes, tornando-o um profissional melhor, acima de tudo, um cidadão mais consciente de suas obrigações.

Assumir valores e princípios éticos em qualquer situação: respeito à diversidade, tolerância, solidariedade, responsabilidade pessoal e social.

A reflexão contínua sobre as próprias ações e ser capaz de tomar decisões adequadas nos diferentes aspectos da vida e na empresa.

Ser capaz de enfrentar os mais diversos desafios que demandam esforço pessoal e superação de limitações e dificuldades.

A capacidade em refletir e estabelecer relações entre informações e conhecimentos, fazer generalizações, contextualizar os saberes adquiridos e utilizá-los conforme a necessidade.

Fazer uma escolha profissional compatível com suas características e interesses pessoais.

O desenvolvimento dos diferentes usos da linguagem: a capacidade de ler, escrever, falar em público e analisar criticamente o que ouve, vê e lê. (BRANCO, 2019, p .25).

O processo educacional do planejamento pedagógico para ter sucesso precisa ser internalizado para alcançar e ampliar a competitividade. Cabe ao pedagogo empresarial "ao estudar e analisar os métodos e tipos de inteligências torna-se mais fácil perceber onde, quando e quem poderá fazer parte do processo de transformação no ambiente organizacional”, Pereira (2019, p.89), e desenvolver uma liderança com uma linguagem simples e compreensível, se faz necessário catalogar os diversos tipos de comportamentos, conhecimentos e certas habilidades que devem contribuir para a orientação dessa jornada, em diversas circunstâncias parece ser difícil e muito desgastante o desenvolvimento da gestão no que concerne as equipes de trabalho.

Reeducar é um processo lento que exige determinação, empenho e dedicação, o pedagogo estará lidando com diversas pessoas com diversos temperamentos e origens sócias distintas, em seu projeto pedagógico ele deve levar isso em consideração, além de outras questões pertinentes ao processo comportamental das pessoas para a condução do trabalho em equipe, "se faz a construção de um processo de aprendizagem que envolve cinco disciplinas: domínio pessoal, visão compartilhada, modelos mentais, aprendizagem em equipe e pensamento sistêmico", Morellato (2020, p. 79), o trabalho exige por via regra que as atividades em equipes agregam as atitudes como elemento primordial para a obtenção dos resultados, "liderança não é poder. Seu papel é se relacionar com toda a equipe fazendo com que elas busquem seus objetivos. O bom líder é aquele que trabalha junto com a sua equipe trazendo excelentes resultados”. Barbosa (2018, p. 175). Uma organização empresarial de destaque, conta com uma equipe vencedora, Branco faz a seguinte declaração: 
A competitividade empresarial associada a uma nova orientação pedagógica de ensino-aprendizagem corporativa é fundamentada no trabalho em equipe, no interrelacionamento pessoal, das competências gerenciais e capacidades cognitivas, formando um arcabouço teórico-prático que poderá tornar a empresa mais competitiva. (BRANCO, 2019, p. 18).

Em relação ao desenvolvimento e criação de equipes, os líderes possuem um papel fundamental, diretores, presidentes e ou membros de conselhos de empresas são unânimes em afirmar que o verdadeiro ponto fraco de uma corporação é uma liderança despreparada. Todo líder é um gestor de pessoas, “o gestor de pessoas, quando exerce a função de líder, contribui de forma essencial para que tanto a empresa como os colaboradores alcancem seus propósitos", Fernandes e Oliveira (2018, p. 92), o sentido de uma liderança autentica e verdadeira, é ter a prerrogativa de conhecer a motivação do ser humano, pois desta forma, será possível orientar os colaboradores no processo educacional.

\section{METODOLOGIA}

Estabelecer um organograma de levantamento de informações mediante a pesquisa bibliográfica. Objetivando alcançar resultados que possam colaborar com a investigação do Pedagogo em sua atuação nas organizações empresariais na formação de líderes, como afirma:

Tratando-se de um ambiente empresarial, a tarefa do pedagogo é fazer com que o chefe/ líder empresário, note que seu ideal de vida, suas aspirações e objetivos pessoais são correspondentes às questões éticas e sociais da empresa, fazendo com que eles se conscientizem que educadores como líderes conseguem melhores resultados. (PIUNA, 2016, p. 7).

É necessário a esquadrinhadura das verdadeiras atribuições e cosmovisão do processo educativo implementado pelo Pedagogo Empresarial, o estudo adotado neste presente artigo será bibliograficamente investigativo. Como método inicial, já citado, bibliograficamente será realizada uma revisão, fundamentada com dados eletrônicos e literários identificando o caminho que posicionou estrategicamente a educação no meio corporativista, gerando a imersão de profissionais da Pedagogia responsáveis pelo processo de Gestão de Pessoas e treinamento de líderes, como afirma Piuna:

O pedagogo em uma empresa é utilizado como instrumento de educação, com conhecimentos para identificar, selecionar e desenvolver indivíduos para o âmbito empresarial, com competências de atuação em Recursos Humanos; sua finalidade é a busca de estratégias e metodologias para garantir o ganho e aumento de conhecimento, para que - assim - possa causar mudanças no comportamento das pessoas, melhorando a qualidade de atuação tanto profissional quanto pessoal. (PIUNA, 2016, p.7).

Considerando a orientação de Lukoseviciu, sobre o projeto de pesquisa: 
Deve-se buscar as fronteiras do conhecimento (estado da arte), pois tal medida visa evitar a duplicação de pesquisas sobre o mesmo enfoque. Nesse percurso, passa-se pelas referências clássicas, por exemplo, os primeiros artigos e livros sobre o assunto, seguindo em direção aos estudos mais recentes sobre o tema/problema. (LUKOSEVICIU, 2018, p.41-42).

Considerando que a afirmação de Antunes que fala sobre "a metodologia qualitativa aparece como uma forma de fazer ciência que caracteriza, essencialmente, as ciências sociais e que reponde a essa preocupação de procura de significados e explicação de processos". Antunes, (2016, p. 525), a mesma contempla o caráter da presente pesquisa.

\section{CONSIDERAÇÕES FINAIS}

Considerando um mundo globalizado com uma mudança veloz de informação e conhecimento, compreende-se que na esfera da construção do saber e ou do conhecimento o pedagogo empresarial em uma organização é o único habilitado para essa nobre tarefa, todo o seu aprendizado e conhecimento obtido na construção de sua formação que lhe faculta perceber o funcionário em seu ambiente empresarial e em sua perspectiva social como afirma Branco:

As empresas precisam reconhecer a importância do pedagogo na empresa por tratarse de um profissional habilitado para trabalhar com a educação corporativa, porque é mais vantajoso e lucrativo manter um funcionário melhor qualificado, visto que, a capacitação profissional o motivará a crescer e a produzir mais na empresa e na vida pessoal. (BRANCO, 2019, p.28).

Partindo deste ponto, o pedagogo empresarial poderá realizar seu poder de influenciar considerando as limitações do colaborador e vislumbrando o possível crescimento e amadurecimento do mesmo.

A globalização não possui barreiras e nem fronteiras para a concorrência, as organizações tiveram o entendimento que para sobreviverem o diferencial está no capital humano como descreve Silva:

Organizações sempre passam por fases oscilantes no mercado, algumas mais tensas e rígidas, ou mais suaves e flexíveis, aparentemente muitos fatos se repetem correlacionados a economia mundial ou mesmo nacional, no entanto, o diferencial permanece apesar de haver a necessidade de ser estimulado, por se tratar do capital humano. (SILVA, 2016, p. 145).

Para uma organização conseguir se sobressair diante dos concorrentes, foi necessário o investimento em seus colaboradores por meio de formações, cursos técnicos e em alguns casos cursos tecnólogos de nível superior e graduações específicas, melhorando também os processos de comunicação interna permitindo um melhor fluxo informativo. 
Nessa conjuntura "faz-se necessário ter um profissional de pedagogia capaz de lidar com todas essas demandas nos espaços não formais” Morellato (2020, p.69), no mesmo contexto que ele é essencial em uma unidade escolar. A organização por meio de seu pedagogo desenvolverá e aplicará uma estratégia pedagógica enfatizando o processo de ensino e aprendizagem que transformará todo o seu ambiente. $\mathrm{O}$ estabelecimento do processo pedagógico dar-se-á mediante as informações da diagnose dos problemas dos colaboradores, visando à superação dos mesmos e desenvolvendo a eficiência e eficácia no desempenho de suas funções.

Em suas ações variadas e complexas o profissional da pedagogia segue as orientações da organização no que tange às suas necessidades, considerando a multiplicidade de necessidades o pedagogo pode intervir com uma metodologia e processos de treinamento e formação de líderes. O pedagogo empresarial por meio de seus conhecimentos, técnicas e métodos treinará os líderes considerando as necessidades da organização. Nesse contexto os resultados alcançados serão fruto de um trabalho planejado e direcionado de forma conjunta, a liderança deve trabalhar em uniformidade com todos os setores da organização com uma participação efetiva considerando a obtenção de novos conhecimentos para os colaboradores e garantido o sucesso da organização. É de suma importância salientar que o pedagogo empresarial consiga o reconhecimento e a importância relevante de seu trabalho.

\section{REFERÊNCIAS}

AGUIAR, Lucas. MACHADO, Claudia C. L. Liderança Sustentável em Empresas Privadas do Paraná, em Especial do Aglomerado Urbano de Curitiba e Campos Gerais. Paraná: FAE Centro Universitário | Núcleo de Pesquisa Acadêmica - NPA, p. 86-99, 2017.

ALVES, Lissandra Cavalcanti. A Pedagogia no Espaço Empresarial: A Função do Pedagogo no Meio Corporativo. João Pessoa: UFPB, 2018.

ANTONIK, Luis Roberto. Compliance, Ética, Responsabilidade Social e Empresarial Uma Visão Prática. Rio de Janeiro: Alta Books, 2016.

ANTUNES, Ana P. XAVIER, Joana O. BORGES, Africa. DORTA, Manuela Rodríguez. NAVEIRAS, Helena Rodríguez. CADENAS, Maria. ALMEIDA, Ana T. MIRANDA, Cláudia. O Enfoque Qualitativo na Avaliação de Programas Psicoeducativos: Aplicação e Contributos da Metodologia Qualitativa. Portugal: Investigação Qualitativa em Ciências Sociais, v. 3, p. 524-533, 2016.

BARBOSA, Jonatan Gabriel. A Influência do Leader Coach no Processo de Desenvolvimento de Liderança. Gestão, Inovação e Empreendedorismo, v. 1, n. 1, Ago. 2018, p. 171-185.

BORELLI, Regina. Liderança e Desenvolvimento de Equipes. São Paulo: Senac, 2018. 
BRANCO, Valdec Romero Castelo. A Pedagogia Empresarial, a Educação Corporativa e a Gestão de Pessoas. Revista Educação, v.14, n.1, 2019.

CARPES, Aletéia de Moura. MAZZARDO, Rodrigo. RIZZATTI, Andrea Bach. SOARES, Soraya de Souza. SILVA, Ana Carolina Cozza J. da. RODRIGUES, Valéria. The Coaching Leadership in the Media. Intern. Journal of Profess. Bus. Review; São Paulo V.2 N.2 2017, pp. 36-51, Jul/Dec.

CHIAVENATO, Idalberto. Introdução à Teoria Geral de Administração. 9a ed. São Paulo: Manole, 2015.

CUNHA, Norival Carvalho. ROCHA, Marcos Antônio. COSTA, Leonardo Ferreira da. BALBINO, Matheus Felipe Barcelos. MENDES, Lúcia Regina. Liderança: Administração do Desempenho. Getec, v.7, n.15, p.1-15/2018.

DANTAS, Cássia Machado Ribeiro; SCHMITZ, Heike. Educação \& Formação, Fortaleza, v. 1, n. 1, p. 124-139, jan./abr. 2016 Programa de Pós-Graduação em Educação da UECE http://seer.uece.br/?journal=redufor $\quad$ ISSN: $2448-3583$; http://dx.doi.org/10.25053/edufor.v1i1.1517 Acessado em 08/03/2020 19h53.

FERNANDES, Felipe Abreu dos Santos. OLIVEIRA, Gabriel Duarte. Análise da Importância da Liderança na Gestão de Pessoas em Equipes de Desenvolvimento de Projetos. São Paulo: Anais do Encontro Nacional de Pós-Graduação VII ENPG Vol.2, p. 91-95, 2018.

FONSECA, Wilson Lima Saraiva da. Revista Eletrônica de Ciências Empresariais Ano 8, No. 12 - Jan/Dez. 2016.

FORCIONE, T. L.; BARBATO, S. B. Posicionamentos em formação profissional continuada: um estudo multimétodo longitudinal. Linhas Crí-ticas, [S. 1.], v. 23, n. 51, p. 351-368, 2018. DOI: $\quad 10.26512 / \mathrm{lc}$ v23i51.8228. Disponível em: https://www.periodicos.unb.br/index.php/linhascriticas/article/view/8228. Acesso em: 9 jul. 2021.

KOTTER, John P. Liderando Mudanças: Transformando Empresas com Forças e Emoções. Rio de Janeiro: Alta Books, 2017.

LIMA, Wilson Saraiva da Fonseca. Revista Eletrônica de Ciências Empresariais Ano 8, No. 12 Jan/Dez. 2016.

LOPES, L. 13 coisas que um líder não deve fazer de jeito algum. Disponível em: https://blog.runrun.it/13-coisas-que-um-lider-nao-deve-fazer/. Acesso em: 11/07/2021.

LUKOSEVICIU, Alessandro Prudêncio. Executar é Preciso, Planejar não é Preciso: Proposta de Framewok para Projetos de Pesquisa. Rio de Janeiro: Administração: Ensino e Pesquisa v. 19 n. 1 p. 32-65 jan-abr, 2018.

MARQUES, J. R. Os 6 Principais Tipos de Líder. Disponível em: https://www.jrmcoaching.com.br/blog/os-6-principais-tipos-de-lider/. Acesso em: 12/07/2021.

MENDONÇA, Bruno. A importância de um profissional de pedagogia empresarial https://www.edools.com/pedagogia-empresarial/. Acessado em 09/03/2020.

MOREIRA, Larissa da Silva. SILVA, Marcos Aurélio Maia. Estilo de Liderança dos Coordenadores da Diretoria de Pessoas \& Gestão em uma Empresa do Seguimento Alimentício 
Localizada em Fortaleza. Revista de Administração da UNI7, Fortaleza, v. 1, n. 2, p. 247-278, jul./dez. 2017.

MOREllato, J. L. H.; SilvA, M. P. A. C.; CUNHA, T. C. O.; PUGliA, V. M. S. A atuação do pedagogo nos espaços não escolares no município de Campos dos Goytacazes, RJ. Perspectivas Online: Humanas \& Sociais Aplicadas, v.10, n.27, p.63 - 832020.

NASCIMENTO, Luane Furtado. BRYTO, Klêner Kleni. A influência da liderança na produtividade organizacional: Estudo de caso na empresa Solus Tecnologia. Revista de Administração e Contabilidade da Faculdade Estácio do Pará-Belém v. 6, n. 11, p. 31-44, jun. 2019, ISSN 2358-1948.

PEREIRA, Maurício da Silva. MELO, Hosana da Silva de. SOARES, Leandra Cristina Cavina P. NOLASCO, Genilson Rosa Severino. A Importância da Inteligência Emocional na Liderança e a sua Relação com o Ambiente Organizacional. Revista Humanidades e Inovação v.6, n.8, p. 87-121, 2019.

PIUNA, Geisa Morais Piuna. PURIFICAÇÃO, Marcelo Máximo. SANTANA, Maria Luzia da Silva. Pedagogia Empresarial: O Desenvolvimento Eficiente de Atividades Pedagógicas no Mercado de Trabalho - A Abertura para Novas Atividades. Goiás: I Colóquio Estadual de Pesquisa Multidisciplinar, p. 1-12, 2016.

ROMERO, Valdec Castelo Branco. Revista Educação v.14, n.1, 2019.

ROVER, Aires José. CELLA, José Renato Gaziero. LEITE, Marcos. RIBEIRO, Maria de Fátima. LASALA, Pilar. Direito, Gorvenança, novas Tecnologias e Desenvolvimento Econômico Sustentável, Globalização e Transformações na Ordem Social e Econômica. Zaragoza: Prensas de la Universidad de Zaragosa, 2019.

SEVERO, J. L. R. L. A formação inicial de pedagogos para a educação em contextos não escolares: apontamentos críticos e alternativas curriculares. In: SILVESTRE, M. A.; PINTO, U. A. (org.). Curso de pedagogia: avanços e limites após as Diretrizes Curriculares Nacionais. São Paulo: Cortez, 2017.

SHINYASHIKI, E. Em 2017, Você Irá Liderar ou Educar? Disponível em: https://superempreendedores.com/empreendedorismo/lideranca/em-2017-seja-um-lidereducador/. Acesso em: 12/07/2021.

SILVA, Alan Miranda. VIVALDI, Guilherme Augusto Dionísio. PIUCORSKY, Fabrício Pelloso. PORTUGAL, Nilton dos Santos. JUNIOR, Pedro dos Santos Portugal. Gestão de Pessoas como Alicerce nas Organizações: Aspectos Relevantes na Condução do Capital Humano. São Paulo: Revista Conbrad, v.1, n.1, p. 137-156, 2016.

SILVA, Rita de Cássia de Lima da. SOUZA, Wanessa Maria Paiva de. Atuação do Pedagogo na Empresa: Uma Intervenção Pedagógica na Área de Treinamento de Novos Funcionários. Environmental Smoke v.1, n. 1, p. 87-113, 2018.

TORRES, Maria Lícia. VILELA, Mônica da Silva Barria. Os Saberes Necessários do Pedagogo para Atuar em Organizações Empresariais. Revista Khora, V. 5, n. 6 (2018) ISSN: 2358-9159.

WHEELER, Alina. Design de Identidade de Marca. $5^{\text {a }}$ ed. Porto Alegre: Bookman, 2019.

ULRICH, David. SMALLWOOD, Norm. Sustentabilidade da Liderança. Rio de Janeiro: Alta Books, 2019. 